05

\title{
Образование бескарбидного бейнита в высокоуглеродистой кремнистой стали при изотермических условиях
}

\author{
(C) Н.А. Терещенко ${ }^{1}$, И.Л. Яковлева ${ }^{1}$, Д.А. Мирзаев ${ }^{2}$, \\ И.В. Булдашев ${ }^{2}$ \\ ${ }^{1}$ Институт физики металлов УрО РАН, Екатеринбург \\ ${ }^{2}$ Южно-Уральский государственный университет, Челябинск \\ E-mail: labmet@imp.uran.ru
}

Поступило в Редакцию 7 июня 2017 г.

Показано, что в высокоуглеродистой стали системы $\mathrm{Fe}-\mathrm{Si}-\mathrm{Mn}-\mathrm{Cr}-\mathrm{V}$ при использовании традиционного печного оборудования возможно получение структуры бескарбидного бейнита. Методами рентгеноструктурного анализа и просвечивающей электронной микроскопии исследован структурный аспект бейнитного превращения, развивающегося в изотермических условиях при $300^{\circ} \mathrm{C}$. Установлена ориентационная связь между кристаллическими решетками $\gamma$ - и $\alpha$-фаз. Определена сверхравновесная концентрация углерода в бейнитной $\alpha$-фазе.

DOI: 10.21883/PJTF.2017.24.45335.16908

Полиморфизм железа является основой металловедческого подхода при создании сталей с различным уровнем механических и эксплуатационных свойств. Протекание превращения $\gamma \rightarrow \alpha$ в сочетании с легированием дает возможность целенаправленного регулирования свойств за счет изменения микроструктуры в процессе термической обработки [1]. По мере понижения температуры механизм превращения аустенита меняется от диффузионного к мартенситному. Ниже перлитного, но выше интервала мартенситного превращения располагается область температур, при которых распад переохлажденного аустенита осуществляется по промежуточной ступени и приводит к образованию бейнита. Среди разнообразных морфологических форм бейнита наибольший интерес представляет структура нижнего бескарбидного бейнита, для которой характерно уникальное сочетание прочности, вязкости и трещиностойкости [2-4]. 
Для высокоуглеродистых инструментальных сталей типа AISI 52100 (ШХ15СГ) показано [5], что получение структуры бескарбидного бейнита не только формирует комплекс повышенных механических характеристик в сравнении с традиционной для таких материалов структурой отпущенного мартенсита, но также обеспечивает точность геометрических размеров изделий при изготовлении и их постоянство при эксплуатации. Однако природа бейнитного превращения в таких сталях в настоящее время остается во многом дискуссионной, а потому нуждается в дальнейших исследованиях.

Цель настоящей работы состоит в том, чтобы взаимодополняющими методами дилатометрии, рентгеноструктурного анализа и просвечивающей электронной микроскопии исследовать механизм превращения $\gamma \rightarrow \alpha$, а также установить возможность получения в инструментальных сталях структуры нижнего бескарбидного бейнита в сочетании со стабильным остаточным аустенитом.

Материалом для исследования служила сталь, химический состав которой включает (at. \%): $4.27 \mathrm{C}, 2.67 \mathrm{Si}, 1.6 \mathrm{Mn}, 1.44 \mathrm{Cr}, 0.11 \mathrm{~V}$, остальное Fе. Выплавленный слиток был подвергнут гомогенизации и прокован на прутки. Дилатометрические измерения проводились на образцах диаметром $3 \mathrm{~mm}$ и длиной $10 \mathrm{~mm}$ с помощью автоматизированного цифрового дилатометра „Linseis L78 R.I.T.A.“ в интервале температур от $900^{\circ} \mathrm{C}$ до комнатной.

При термической обработке заготовок сечением $12 \times 12 \mathrm{~mm}$ для рентгеновских и структурных исследований использовались лабораторные печи с окислительной атмосферой. Закалка на мартенсит выполнялась путем охлаждения от $900^{\circ} \mathrm{C}$ в воде. Схема обработки для получения структуры бескарбидного бейнита включала нагрев до $900^{\circ} \mathrm{C}$, подстуживание до $300^{\circ} \mathrm{C}$, изотермическую выдержку при $300^{\circ} \mathrm{C}$ продолжительностью от 10 до $30 \mathrm{~h}$, охлаждение в воде.

Для рентгеноструктурного анализа использовался дифрактометр ДРОН-УМ1. Запись дифрактограмм проводилась в $K_{\alpha}$-излучении трубки с железным анодом при напряжении $30 \mathrm{kV}$ и величине тока $20 \mathrm{~mA}$ в шаговом режиме через угол $2 \theta=0.02 \mathrm{deg}$ с набором импульсов в течение $10 \mathrm{~s}$. Тонкая структура стали и ориентационные соотношения между $\alpha$ - и $\gamma$-фазами изучались методом просвечивающей электронной микроскопии с применением дифракционного и темнопольного анализа на микроскопе „ЈЕM-200СХ“.

Письма в ЖТФ, 2017, том 43, вып. 24 


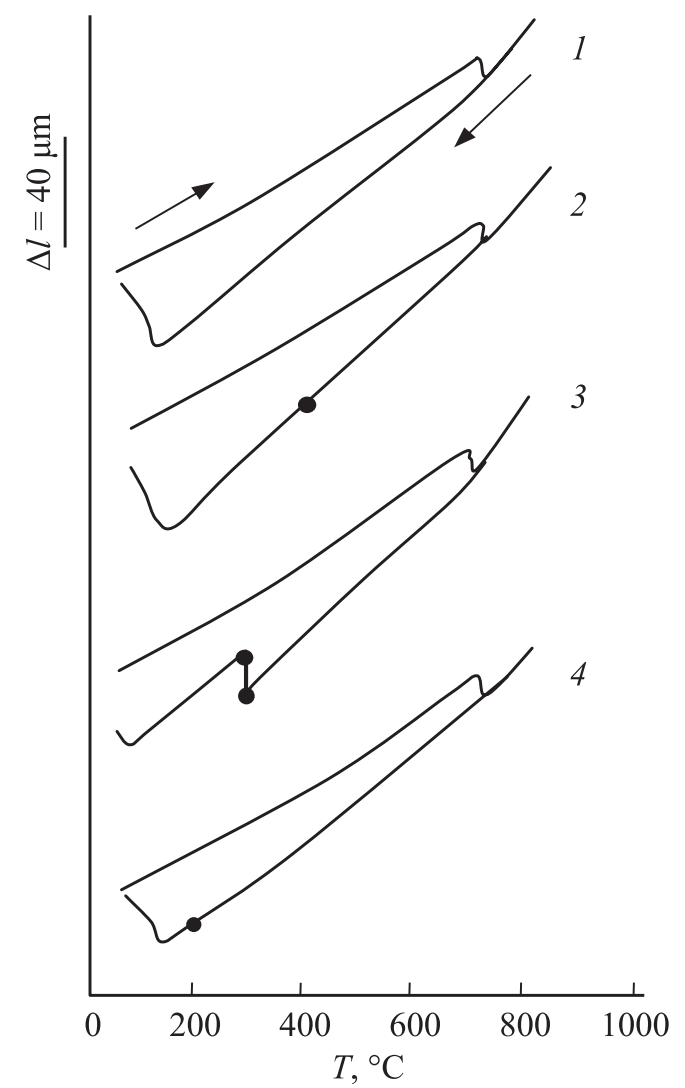

Рис. 1. Дилатометрические кривые стали $\mathrm{C}-\mathrm{Si}-\mathrm{Mn}-\mathrm{Cr}-\mathrm{V}$, подвергнутой термической обработке по различным схемам: 1 - закалка, 2 - изотермическая выдержка при $400^{\circ} \mathrm{C}, 3-$ изотермическая выдержка при $300^{\circ} \mathrm{C}$, 4 - изотермическая выдержка при $200^{\circ} \mathrm{C}$.

Термическое воздействие в дилатометре включало единые для всех образцов условия аустенитизации: нагрев до $900^{\circ} \mathrm{C}$ и выдержку в течение $600 \mathrm{~s}$. Изменение длины образцов $\Delta l$ в зависимости от температуры представлено на рис. 1; восходящие ветви на дилатометрических кривых свидетельствуют о том, что точка $A_{C 1}$ достигается при повышении

Письма в ЖТФ, 2017, том 43, вып. 24 
температуры до $771^{\circ} \mathrm{C}$, интервал превращения $\alpha \rightarrow \gamma$ при скорости нагрева $0.5^{\circ} \mathrm{C} / \mathrm{s}$ составляет менее $35^{\circ} \mathrm{C}$. Температура $900^{\circ} \mathrm{C}$ соответствует существованию аустенита, поэтому последующая выдержка при этой температуре способствует выравниванию химического состава твердого раствора аустенита по углероду.

Охлаждение дилатометрических образцов осуществлялось различным образом. В процессе непрерывного охлаждения от температуры аустенитизации до комнатной (вариант 1 - закалка) высокотемпературная $\gamma$-фаза сохраняется до $M_{s}=90^{\circ} \mathrm{C}$, после чего сталь испытывает мартенситное превращение $\gamma \rightarrow \alpha$ (нисходящая ветвь кривой 1 на рис. 1). Варианты $2-4$ включали охлаждение от $900^{\circ} \mathrm{C}$ до температур $400,300,200^{\circ} \mathrm{C}$ соответственно и изотермическую выдержку при каждой их этих температур в течение $5 \mathrm{~h}$, что условно отмечено на соответствующих дилатометрических кривых темным кружком, далее все образцы также охлаждались до $20^{\circ} \mathrm{C}$.

При охлаждении по варианту 2 длина образца в процессе выдержки при $400^{\circ} \mathrm{C}$ остается неизменной, а температура начала мартенситного превращения несколько повышается по сравнению с аналогичной величиной для закаленного состояния: $M_{s}=101^{\circ} \mathrm{C}$ (кривая 2 на рис. 1). Дестабилизация аустенита обусловлена обеднением твердого раствора аустенита по углероду за счет начальных этапов карбидообразования. При охлаждении по варианту 4 , включающему изотермическую выдержку при температуре $200^{\circ} \mathrm{C}$, форма дилатометрической кривой (в том числе положение точки $M_{s}$ ), идентична форме дилатограммы закаленной стали (кривые 4 и 1 на рис. 1 ). Из этого можно заключить, что диффузионная активность атомов углерода при $200^{\circ} \mathrm{C}$ заметно снижена и в аустените сохраняется исходная концентрация углерода.

Охлаждение по варианту 3 качественно меняет вид дилатограммы. В процессе изотермической выдержки при $300^{\circ} \mathrm{C}$ после инкубационного периода продолжительностью не более 3 min длина дилатометрического образца сокращается пропорционально времени выдержки. По истечении $5 \mathrm{~h}$ на дилатометрической кривой появляется вертикальный участок, высота которого составляет $10 \mu \mathrm{m}$ (кривая 3 на рис. 1). Стабильность непревращенного аустенита существенно возрастает и при последующем охлаждении температура начала мартенситного превращения сдвигается в сторону низких температур $\left(M_{s}=37^{\circ} \mathrm{C}\right.$ против $M_{s}=90^{\circ} \mathrm{C}$ после закалки). Эти данные свидетельствуют о том, что при $300^{\circ} \mathrm{C}$ аустенит характеризуется минимальной устойчивостью

Письма в ЖТФ, 2017, том 43, вып. 24 


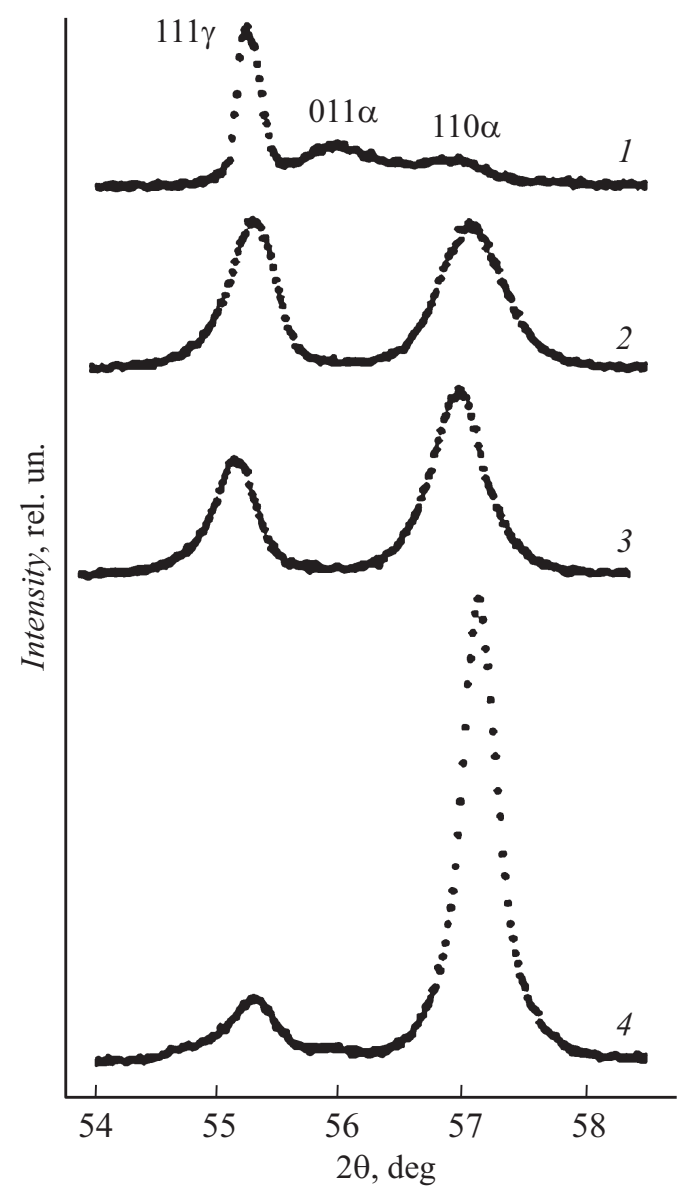

Рис. 2. Фрагменты дифрактограмм стали $\mathrm{C}-\mathrm{Si}-\mathrm{Mn}-\mathrm{Cr}-\mathrm{V}$ после термической обработки в различных режимах: 1 - закалка от $900^{\circ} \mathrm{C}$ с охлаждением в воде; 2-4 - нагрев до $900^{\circ} \mathrm{C}$, подстуживание до $300^{\circ} \mathrm{C}$, изотермическая выдержка $300^{\circ} \mathrm{C}$ в течение $10(2), 20$ (3) и $30 \mathrm{~h}(4)$.

относительно распада по промежуточной ступени и в исследуемой стали интенсивно развивается бейнитное превращение, в ходе которого происходит активное перераспределение углерода между $\alpha$ - и $\gamma$-фазами.

Письма в ЖТФ, 2017, том 43, вып. 24 
О кинетике бейнитного превращения в процессе изотермической выдержки при $300^{\circ} \mathrm{C}$ можно судить по результатам рентгеноструктурного анализа при сравнении с закаленным состоянием исследуемой стали (рис. 2). На дифрактограмме закаленной стали в области углов $2 \theta=54.0-58.5 \mathrm{deg}$ присутствует узкий и высокий интерференционный максимум $111 \gamma$ аустенита; мартенсит представлен хорошо разрешенным дублетом линий $011 \alpha$ и $110 \alpha$ (кривая 1). Величина междублетного расстояния $\Delta \theta 110 \alpha$ соответствует содержанию углерода в мартенсите $C \geqslant 4.0$ at.\%. Она близка к концентрации углерода в химическом составе стали. Это означает, что практически весь углерод, растворенный в аустените при $900^{\circ} \mathrm{C}$, сохранился в решетке мартенсита. Доля мартенсита в структуре стали, оцененная по отношению интенсивностей дифракционных пиков $\gamma$ - и $\alpha$-фаз, составляет $42 \%$.

Расположенные ниже на рис. 2 дифрактограммы 2-4 получены для образцов исследуемой стали после изотермической выдержки при $300^{\circ} \mathrm{C}$ продолжительностью $10,20,30 \mathrm{~h}$ и последующего охлаждения до комнатной температуры. На дифрактограмме 2 передние линии $\gamma$ - и $\alpha$-фаз имеют примерно равную интенсивность. Интерференционный максимум $110 \alpha$ в данном случае представляет собой суперпозицию отражений от двух состояний $\alpha$-фазы с различным содержанием углерода: бейнита и мартенсита. В отличие от закаленного состояния явно выраженный дублет отсутствует, поэтому можно заключить, что доля мартенсита невелика.

После выдержки в течение $20 \mathrm{~h}$ расположенный в области бо́льших углов максимум, принадлежащий $\alpha$-фазе, заметно выше аустенитного и несколько у́же (рис. 2, кривая 3). Такая эволюция картины рентгеновской дифракции обусловлена тем, что в результате изотермического превращения $\gamma \rightarrow \alpha$ количество бейнита в структуре увеличивается, а последующее превращение остаточного аустенита в мартенсит тормозится вследствие стабилизации остаточного аустенита и снижения $M_{s}$. $\mathrm{B}$ стали, выдержанной при $300^{\circ} \mathrm{C}$ в течение $30 \mathrm{~h}$, бейнитная фаза становится преобладающей, ее объемная доля достигает $83 \%$ (кривая 4). Содержание углерода в кристаллической решетке бейнита, оцененное (см. [6]) по уширению максимума $110 \alpha$, составляет примерно 0.64 at.\%. Эта величина, существенно превышающая равновесную концентрацию углерода в феррите, согласуется с данными работы [6], полученными методом атомной зондовой томографии.

Тонкую структуру бейнита, сформировавшегося в изотермических условиях при $300^{\circ} \mathrm{C}$, иллюстрирует рис. 3. На светлопольном изобра-

Письма в ЖТФ, 2017, том 43, вып. 24 


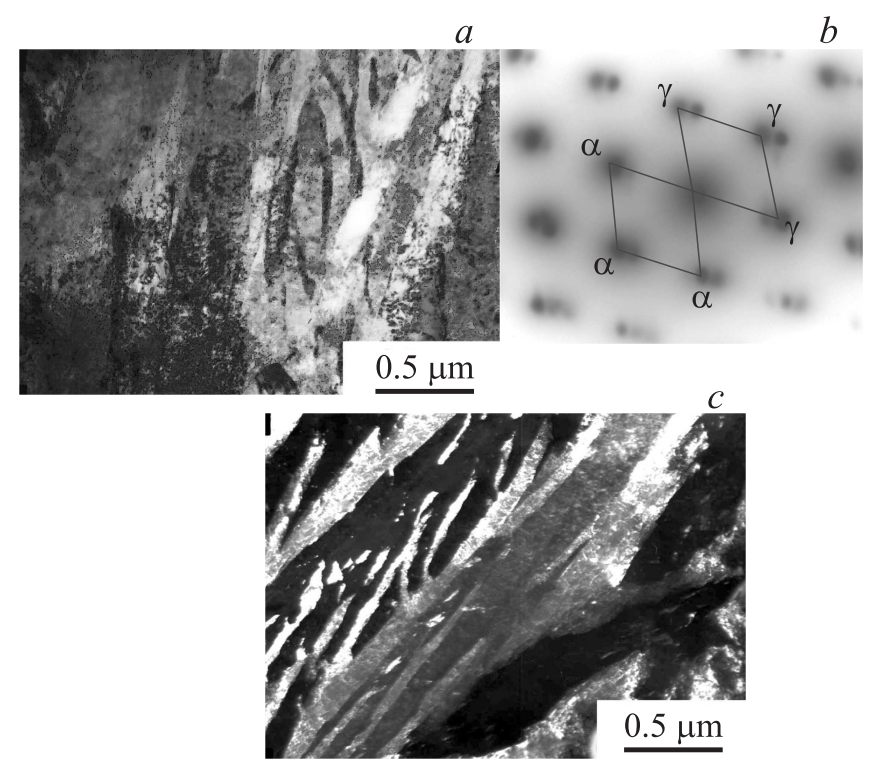

Рис. 3. Структура стали $\mathrm{C}-\mathrm{Si}-\mathrm{Mn}-\mathrm{Cr}-\mathrm{V}$ после термической обработки по схеме нагрев до $900^{\circ} \mathrm{C}$, подстуживание до $300^{\circ} \mathrm{C}$, изотермическая выдержка $300^{\circ} \mathrm{C}$ в течение $30 \mathrm{~h}: a-$ светлопольное изображение, $b-$ электронограмма и схема ее расшифровки, $c$ - темнопольное изображение в рефлекce $020 \gamma$.

жении видны вытянутые в преимущественном направлении элементы структуры переменного контраста, в отдельных областях отмечается повышенная плотность дислокаций (рис. 3,a). На электронограмме, полученной с данного участка, наблюдаются рефлексы $\alpha$ - и $\gamma$-фаз, образующие две подрешетки с осями зон $[110] \gamma$ и $[111] \alpha$ (рис. $3, b$ ). Кристаллические решетки бейнита и аустенита подчиняются ориента-

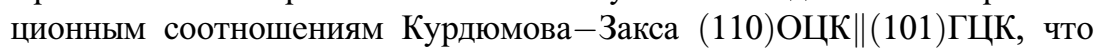
свидетельствует о сдвиговом характере превращения $\gamma \rightarrow \alpha$. Пластинки бейнита толщиной 20-50 nm сгруппированы в пакеты, разделенные тонкими прослойками остаточного аустенита. На темнопольном изображении, полученном в рефлексе $020 \gamma$, кристаллы остаточного аустенита находятся в отражающем положении (рис. 3,c). Отсутствие на дифрак-

Письма в ЖТФ, 2017, том 43, вып. 24 
ционной картине карбидных рефлексов дает основание полагать, что весь углерод распределен между решетками аустенита и бейнита. При этом следует отметить, что в работе [7] для стали близкого химического состава, но содержащей значительно меньше $\mathrm{Mn}$ (0.29 at.\%), было показано, что изотермический распад аустенита при $300^{\circ} \mathrm{C}$ сопровождается выделением частиц цементита и $\varepsilon$-карбида. Поэтому можно предположить, что наряду с легированием кремнием и алюминием марганец также играет важную роль в образовании бескарбидного бейнита.

Итак, в высокоуглеродистой стали системы $\mathrm{Fe}-\mathrm{Si}-\mathrm{Mn}-\mathrm{Cr}-\mathrm{V}$ при использовании традиционного печного оборудования возможно создание структуры на основе бескарбидного бейнита. Данные, полученные прямыми экспериментальными методами, дают основание считать, что бейнитное превращение, развивающееся в переохлажденном аустените в изотермических условиях при $300^{\circ} \mathrm{C}$, осуществляется сдвиговым путем и сопровождается перераспределением углерода между $\gamma$ и $\alpha$-фазами без выделения карбидов. При оценке факторов, способствующих достижению повышенного уровня механических свойств после такой обработки, следует отметить пересыщение $\alpha$-фазы по углероду, дисперсность бейнитных кристаллов, наличие вязких прослоек остаточного аустенита.

Работа выполнена за счет гранта Российского научного фонда (проект № 16-19-10252).

\section{Список литературы}

[1] Счастливцев В.М., Мирзаев Д.А., Яковлева И.Л. Структура термически обрабатываемой стали. М.: Металлургия, 1994. 288 с.

[2] Bhadeshia H.K.D.H. Bainite in steels. London: The Institute of Materials, 2001. $460 \mathrm{p}$.

[3] Caballero F.G., Bhadeshia H.K.D.H. // Current Opinion Solid State Mater. Sci. 2004. V. 8. Iss. 3-4. P. 251-257.

[4] Сарафанов Г.В., Переверзенцев В.Н. // Письма в ЖТФ. 2015. Т. 41. В. 19. C. $105-110$.

[5] Sourmail T., Smanio V. // Acta Mater. 2013. V. 61. Iss. 7. P. 2639-2648.

[6] Caballero F.G., Miller M.K., Garsia-Mateo C., Cornide J., Santofimia M.J. // Scripta Mater. 2012. V. 67. Iss. 10. P. 846-849.

[7] Donazil E., Podravcky T., Svejcar J. // Arch. Eisenhüttewesen. 1982. Bd 52. N 7. S. 289-293.

Письма в ЖТФ, 2017, том 43, вып. 24 